\title{
Estimation of life and Reliability of Electronic Product
}

\author{
Ramesh E Patil ${ }^{1}$, Jerald Leo ${ }^{2}$, Govind R. Kunkolienkar ${ }^{3}$ \\ Student, Department of Electrical and Electronics Engg, Goa collage of Engg, Goa, India ${ }^{1}$ \\ Quality Manager, Siemens Energy and Automation (GOA WORKS), Goa, India ${ }^{2}$ \\ Associate Professor, Department of Electrical and Electronics Engg, Goa collage of Engg, Goa, India ${ }^{3}$
}

\begin{abstract}
Presently, the market not only requires the fault free parts but also requires delivered product to work safely and failure free i.e. reliably. So for prevention of failure of product in between manufacturing stage to final usage stage, we need to do reliability as well as performance testing.Development in the electronic system i.e. VLSI and embedded system using component like FPGA, CPLD increases the reliability issue. So for reducing the reliability issue required to understand root causes of failure which causes failure in the field and further their minimization. Some traditional approaches like MIL-217 are used for reliability prediction but these type of approaches having some limitations like, it does not consider the load profiles, no provisions for root cause of component failure, the consideration of base failure rate and other unclear modifying factors.Prognostics and health management approach (PHM) consider the life cycle loading of the electronic system with its actual working conditions, which is the better tool for reliability predictions. This approach mainly relies on extensively Highly Accelerated Life Testing (HALT). This paper gives an idea about the reliability prediction approach.
\end{abstract}

Keywords: Failure Rate,MTBF(Mean Time Between Failure),MTTF(Mean Time To Failure) FMMEA (Failure Mode Mechanism Effect Analysis),RPN (Risk Priority Number), Accelerated life Testing, Stress Models.

\section{INTRODUCTION}

Mil-HDBK-217, 217-PLUS, Telcordia, PRISM, and FIDES are the traditional reliability prediction methods used for the reliability prediction of electronic system. These methods consider constant failure rate of component with "Pi- factor" modifiers for various conditions i.e. quality, operating and environmental conditions. This is the major difficulty of the traditional methods. So because of the lack of information about the component failure rate, these methods are inaccurate to predict the reliability.

IEEE 1413 standard gives guidelines for reliability prediction methods. The IEEE1413.1 provides a summary of the common methods for reliability prediction of electronic system. As per IEEE 1413.1, reliability predictions methods are 1) Predictions based on field data 2) Predictions based on test data 3)Prediction based on stress and damage models 4)Prediction based on handbooks. As per the application, we can select appropriate reliability prediction method.

The reliability of any component, device or any system has two components i.e. probabilistic and Deterministic. In probabilistic, we can estimate probability of failure and uncertainty in component and in deterministic, we can get the various models and causes of failures. These two components make the reliability prediction process more accurate and simple.

\section{A. Reliability}

Reliability is defined as the probability that a device will perform its required function under stated condition for a specific period of time. A practical definition of reliability is "the probability that a piece of equipment operating under specified conditions shall perform satisfactorily for a given period of time" [1].

Reliability prediction mostly depends upon the correctly defined parameters and distribution of parameters which should be correctly matched with the data. If the distribution of parameter is not proper then the results will not be reliable. Reliability engineering considers more statistics which gives the idea about the product robustness as well as quality of product.

\section{B. Failure rate $(\lambda)$}

The no. of units failing per unit time is nothing but the failure rate of product. This failure rate is different at different stage of life of product which we can be analysed by using bathtub curve, shown in fig 1

The life of units can be divided into three distinct period's 1. Early failure period: the slope of curve from starting to where it begins to flatten can be considered as Early Failure Period. This area shows that initially the failure rate is high but after words its decreases. 


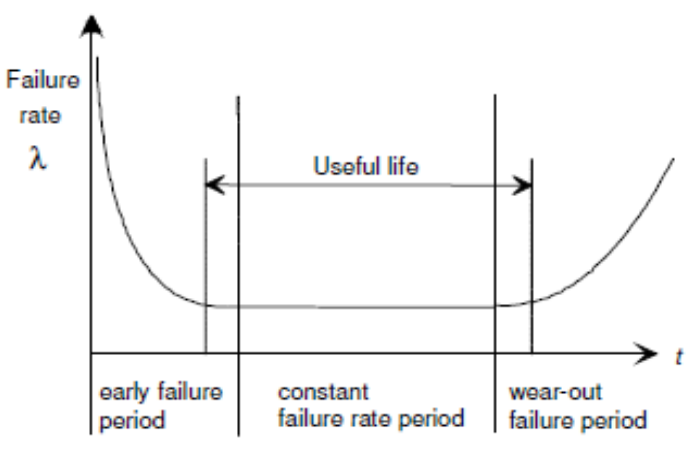

Fig1 Bathtub Curve [1]

2. Useful Life Period: After the early failure period we can observe one flat portion of the graph which is called useful Life Period. In this portion the failure occurs in random sequence but failure rate is predictable hence we can observe that this portion having constant slope.

3. Ware out Failure Period: The last portion of the graph which having increasing slope of failure, causes end of the life of period is called ware out failure period. This happens when the device become old.

C. Mean Time between Failures (MTBF) and Mean Time to Failure (MTTF)

Reliability is quantified as MTBF (Mean Time between Failures) for repairable product and MTTF (Mean Time to Failure) for non-repairable product.

The formula for calculating the MTBF is

$\mathrm{T}=$ total time

$$
\mathrm{MTBF}=\frac{\mathrm{T}}{\mathrm{R}}
$$

$\mathrm{R}=$ number of failures

The formula for calculating MTTF

$\mathrm{T}=$ total time

$$
\mathrm{MTTF}=\frac{\mathrm{T}}{\mathrm{N}}
$$

$\mathrm{N}=$ Number of units under test.

Example: Suppose 20 devices are tested for 1000 hours. During the test 4 failures occur.

The estimate of the MTBF is:

$$
\mathrm{MTBF}=\frac{20 * 1000}{4}=5000 \text { hours } / \text { failure }
$$

Whereas for MTTF

$$
\mathrm{MTTF}=\frac{20 * 1000}{20}=1000 \text { hours } / \text { failure }
$$

If the MTBF is known, one can calculate the failure rate as the inverse of the MTBF. The formula for $(\lambda)$ is:

$$
\lambda=\frac{1}{\theta}=\frac{r}{T}
$$

Where $r$ is the number of failures

Once a MTBF is calculated, if failures occur randomly then they can be described by an exponential distribution

But when $\mathrm{t}=\mathrm{MTBF}$

$$
R(t)=e^{-\lambda t}=e^{\frac{-e}{M T B F}}
$$

$$
R(t)=e^{-1}=0.3677
$$

The exponential term defines the reliability of the module in terms of the calculated MTBF.

\section{PREDICTION OF LIFE AND RELIABILITY OF ELECTRONIC SYSTEM}

Reliability of a component, system or structure has two components. The first one is probabilistic, where the probability of failure and uncertainty in parameters is estimated, while the second one is deterministic which deals with finding various modes and causes of failure. These two aspects together make reliability prediction more accurate and complete ${ }^{[2]}$.

Reliability prediction process consists of following steps 1. Identify the life cycle load Electronic system, Device or component.

2. Identify the failure mode, mechanism and causes, and then identify the models for respective failure mechanism i.e. FMMEA

3. Test the electronic system and monitor the environmental usage data and find the reliability of system in terms of failure or useful life.

Fig 2 shows the basic principle and steps to be followed in reliability prediction.

\section{A. Life cycle Model}

Probabilistic aspect is required to predict the life with acceptable level of uncertainty and deterministic approach to analyse the competing failure mechanisms and identify the dominant failure mechanism that limits the functional capability of the component. Hence, it is important that the life cycle model should address both probabilistic and deterministic aspects of component life cycle.

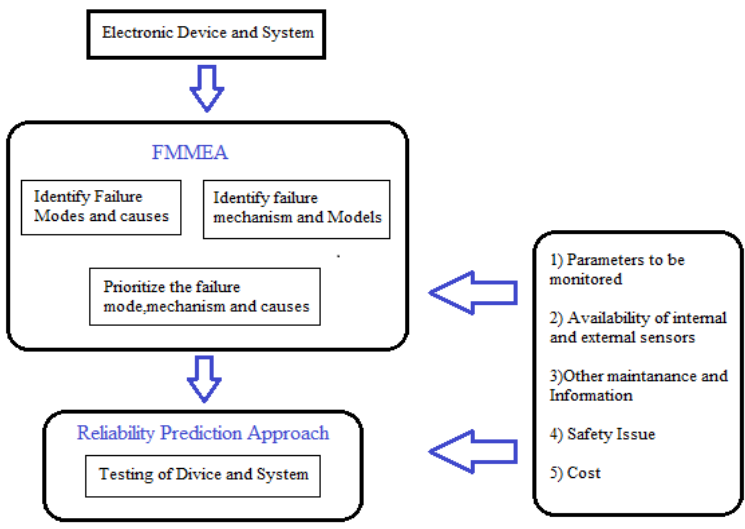

Fig 2 Reliability Prediction for Electronic systems 
From fig. 3 we can understand modified form of application conditions), and their influence on the product traditional bath tub curve depicting three regions i.e. early susceptibility to failure with respect to the use conditions failure, useful life and ware out of life along with the ${ }^{[3]}$. competing failure mechanisms.

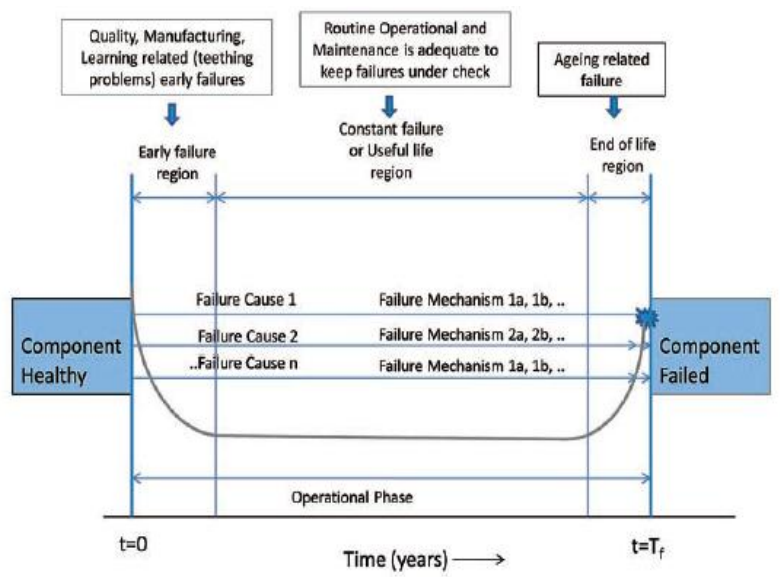

Fig.3 Modified Bath Tub Curves [3]

TABLE I LIFE CYCLE LOADS

\begin{tabular}{|l|l|}
\hline Load & Load Conditions \\
\hline Electrical & Current, voltage, power \\
\hline Mechanical & $\begin{array}{l}\text { Pressure magnitude, pressure } \\
\text { gradient, vibration, shock load, stress }\end{array}$ \\
\hline Thermal & $\begin{array}{l}\text { Steady-state temperature, temperature } \\
\text { ranges, temperature cycles, } \\
\text { temperature gradients, ramp rates, } \\
\text { heat dissipation }\end{array}$ \\
\hline Physical & $\begin{array}{l}\text { Radiation, electromagnetic } \\
\text { interference. }\end{array}$ \\
\hline
\end{tabular}

The life-cycle loads (thermal, mechanical, chemical, electrical, and so on), either individually or in various combinations, may lead to performance or physical degradation of the product and may reduce its service life. The extent and rate of product degradation depends on the magnitude and duration of exposure (usage rate, frequency, and severity) of such loads.

\section{B. Competing Failure Mechanism}

If we see in fig 2 there could be more than one failure mechanism associated with one failure mode. One type failure mode happen due to more than one failure mechanism as well same failure mechanism can contribute to another failure mode.

Failure mechanisms are the processes by which physical, electrical, chemical, and mechanical stresses induce failures individually or in combination. FMMEA is based on an understanding of the relationships between product requirements and the physical characteristics of the product (and their variation in the production process), the interactions of product materials with loads (stresses at

\section{FMMEA Analysis}

Fig 3 shows that the basic steps of FMMEA Methodology. FMMEA uses the loading life cycle of device, operating conditions and duration of application with the considerations of active stresses and failure mechanism. The purpose of FMMEA is to find the failure mode and mechanism for different operating conditions and prioritize the failure mechanism. Prioritization of failure mode and mechanism depends upon the RPN (Risk Priority Number) which is calculated for different failure mechanism. If higher the RPN then higher the rank of failure mechanism among the other failure mechanisms hence we can decide the most probable failure mechanism.

The RPN is the product of the probability of detection, occurrence and severity of each mechanism. Occurrence gives the idea about the how frequently the failure mechanism will occur. Severity decides the effect of failure mechanism and detection decides the probability of detection of failure modes and mechanism.fig 4 shows the three dimensional matrix of RPN.

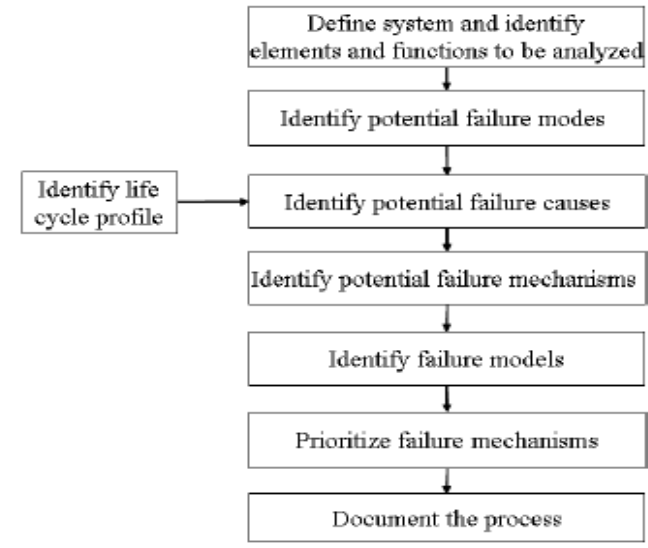

Fig 4 FMMEA Methodology [1]

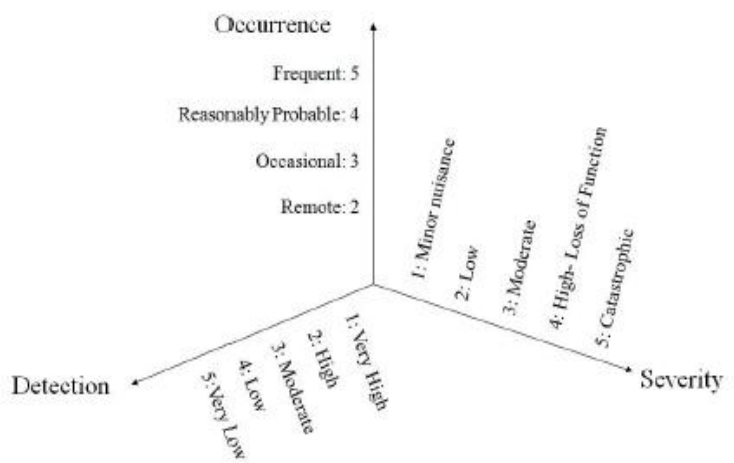

Fig 5 RPN Matrix [1] 


\author{
National Conference on Advances in Electrical Engineering \\ NMAM Institute of Technology, Nitte
}

Vol. 5, Special Issue 2, April 2017

D. FMMEA in Reliability Prediction Approach:

Fig.5 shows the basic principle of FMMEA methodology used in different reliability prediction approaches. The first in Reliability prediction approach involves FMMEA, where design data, life cycle loading and environmental conditions are the input. Life cycle loading of product can be electrical, mechanical, and thermal or chemical in nature. Environmental Conditions of product consider all conditions of product starting from manufacturing to use conditions. FMMEA block identifies the failure modes, mechanism, causes and models. Life cycle load data used in failure models for calculation of degradation of product useful remaining life of product. After the FMMEA, testing approach will followin which the Environmental and usage data with different test conditions and calculation of useful remaining life of the product are monitored. Also in reliability prediction approach, we need to concentrate on the available resources, safety issue and majorly cost required for testing. In reliability prediction methods main difficulty is the available resources and cost required for the process.

\section{III.APPROACH}

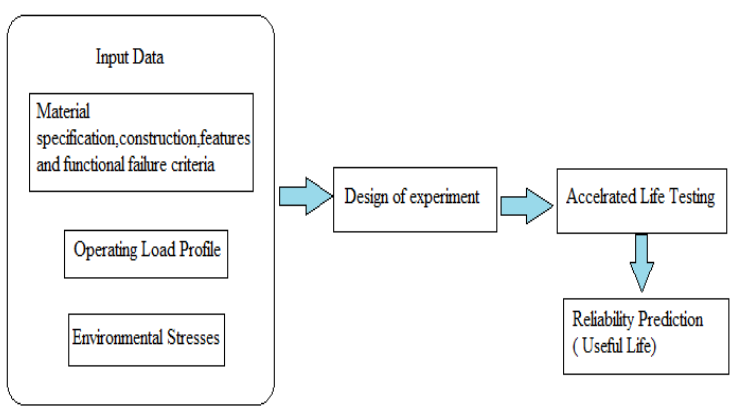

Fig.6 Reliability Prediction Approach

\section{A. Input:}

In this stage all input data like material properties, operational load profile e.g. no of operational cycle, current and voltage characteristics, power supply quality, design and constructional features of component, test and maintenance provisions etc. should be collected.

\section{B. Design of Experiment:}

For effective planning and execution, for characterizing the reliability attributes of the components, it is very important to optimize all the test parameters. This approach gives idea about the selection of test parameters which helps to find out the failure mechanism under consideration, as well not includes any failure mode which is not possible in actual use condition.

\section{Accelerated Life Testing}

The basic principle of accelerated life testing of 1) Define the failure mechanisms and mode of failure in components or systems is that it considers the influence of the product to be tested. Remembering that the majority of stress in reducing the life of the component. Hence it is required to monitor and log the test parameters in on- line mode. The accelerated test also provides the information on degradation of the component ${ }^{[2]}$.

\section{TABLE I FMMEA OF ELECTRONIC COMPONENT ${ }^{[4]}$}

\begin{tabular}{|c|c|c|c|}
\hline Element & $\begin{array}{c}\text { Potential Failure } \\
\text { Mode }\end{array}$ & $\begin{array}{c}\text { Potential Failure } \\
\text { Cause }\end{array}$ & $\begin{array}{l}\text { Potential Failure } \\
\text { Mechanism }\end{array}$ \\
\hline Resistor & Open Circuit & High Temperatuse & Over voltage \\
\hline \multirow[t]{2}{*}{ Capacitor } & Drop in Capacitance & $\begin{array}{l}\text { Electrolyte } \\
\text { Leakage }\end{array}$ & Aging of Electrolyte \\
\hline & Short Circuit & High Voltage & Dielectric Breakdown \\
\hline Inductor & $\begin{array}{l}\text { Short Open befween } \\
\text { Windings and Core }\end{array}$ & High Temperature & $\begin{array}{l}\text { Wearout of Winding } \\
\text { Insulation }\end{array}$ \\
\hline $\begin{array}{l}\text { Input/ Output } \\
\text { Fuse Wire }\end{array}$ & Open Circuit & High Temperature & $\begin{array}{l}\text { Wire Melting due to } \\
\text { Current Overload }\end{array}$ \\
\hline \multirow{3}{*}{ Diode } & Die Fracture & $\begin{array}{l}\text { Temperature } \\
\text { Cycling }\end{array}$ & Thermal fatigue \\
\hline & Short Circuit & $\begin{array}{l}\text { High Temperature, } \\
\text { Current Density }\end{array}$ & Contact Migration \\
\hline & Thermal Runaway & $\begin{array}{l}\text { High Temperature } \\
\text { due to Resistive } \\
\text { Heating }\end{array}$ & Thermal Runaway \\
\hline \multirow{4}{*}{$\begin{array}{l}\text { Power } \\
\text { MOSFET }\end{array}$} & Gate Oxide Short & $\begin{array}{l}\text { High Temperature } \\
\text { and Voltage }\end{array}$ & $\begin{array}{l}\text { Time Dependent } \\
\text { Dielectric Breakdown }\end{array}$ \\
\hline & $\begin{array}{l}\text { Gate Oxide } \\
\text { Breakdown }\end{array}$ & High Voltage & EOS, ESD \\
\hline & $\begin{array}{l}\text { Change of Leakage } \\
\text { Current }\end{array}$ & $\begin{array}{l}\text { High Current } \\
\text { Density }\end{array}$ & Hot Carrier \\
\hline & Thermal Runaway & $\begin{array}{l}\text { High Temperanure } \\
\text { Because of } \\
\text { Resistive Heating }\end{array}$ & Thermal Runaway \\
\hline Transformer & $\begin{array}{l}\text { Short Open between } \\
\text { Windings and Core }\end{array}$ & High Temperatuse & $\begin{array}{l}\text { Wearout of Winding } \\
\text { Insulation }\end{array}$ \\
\hline \multirow{3}{*}{ Metallization } & \multirow{3}{*}{$\begin{array}{l}\text { Electrical } \\
\text { Short Open, Cange } \\
\text { in Resistance in } \\
\text { Metallization Traces }\end{array}$} & High Temperanare & Electromigration \\
\hline & & \begin{tabular}{|l|} 
High Relative \\
Humidity \\
\end{tabular} & Corrosion \\
\hline & & $\begin{array}{l}\text { Ionic } \\
\text { Contamination }\end{array}$ & Contamination \\
\hline \multirow{7}{*}{$\begin{array}{l}\text { Integrated } \\
\text { Circuat }\end{array}$} & \multirow{2}{*}{$\begin{array}{l}\text { Open Circuit in } \\
\text { Wirebond }\end{array}$} & High Temperature & $\begin{array}{l}\text { Wire Melting due to } \\
\text { Current Overload }\end{array}$ \\
\hline & & $\begin{array}{l}\text { Temperafure } \\
\text { Cycling }\end{array}$ & $\begin{array}{l}\text { Wire breakage due to } \\
\text { thermal cycling } \\
\end{array}$ \\
\hline & \multirow{2}{*}{$\begin{array}{l}\text { Open Circuit/Short } \\
\text { Creuit in Die } \\
\text { Metallization }\end{array}$} & High Temperanuse & Resistive Heating \\
\hline & & High Temperature & Electromigration \\
\hline & $\begin{array}{l}\text { Change of Leakage } \\
\text { Current }\end{array}$ & High Electric Field & Hot Carriet \\
\hline & $\begin{array}{l}\text { Gate Oxide Short } \\
\text { Circuit }\end{array}$ & High Voltage & $\begin{array}{l}\text { Time Dependeat } \\
\text { Dielectric Breakdown }\end{array}$ \\
\hline & Die Fracture & $\begin{array}{l}\text { Temperature } \\
\text { Cyeling }\end{array}$ & $\begin{array}{l}\text { Crack Initiation and } \\
\text { Propagation }\end{array}$ \\
\hline \multirow{4}{*}{$\begin{array}{l}\text { Printed Curcuit } \\
\text { Board }\end{array}$} & \multirow{2}{*}{ Crack/ Fracture } & Sudden Impact & Shock \\
\hline & & Random Vibratioa & Fatigue \\
\hline & \begin{tabular}{|l|} 
Loss of Polymer \\
Strength
\end{tabular} & High Temperanse & Glass Transition \\
\hline & Shont circuit & $\begin{array}{l}\text { Humidity and } \\
\text { Current }\end{array}$ & $\begin{array}{l}\text { Conductive Filament } \\
\text { Formation }\end{array}$ \\
\hline
\end{tabular}

Constructing an accurate quantitative accelerated test requires the following steps: 


\author{
National Conference on Advances in Electrical Engineering \\ NMAM Institute of Technology, Nitte \\ Vol. 5, Special Issue 2, April 2017
}

"electrical failures" are basically mechanical or chemical in nature.

2) Study the product working environment and Determine the environmental stresses in which the product will be exposed when operating and when not operating or stored.

3) Based on the failure mechanisms select a test, or combination of tests, that will accelerate that failure mechanism(s).

4) Relevant acceleration models that should be considered include:

- Arrhenius Temperature Acceleration for temperature and chemical aging effects

- Inverse Power Law for any given stress

- Miner's Rule for linear accumulated fatigue damage

- Coffin-Manson non-linear mechanical fatigue damage

- Peck's Model for temperature and humidity combined effects

- Eyring/Black/Kenney models for temperature and voltage acceleration

\section{IV.ROOT CAUSE ANALYSIS AND DIFFERENT STRESS MODELS}

The root cause of failure indicates that the basic cause of the system failure is component failure; further analysis is required as to why the component failed.

It is recommended that before selecting a Stress model, one should determine the type of available sensory data, the system level at which health assessment would be made, the number of system's performance parameters available for monitoring, and the ability to monitor system's environment and operating conditions.

The data-driven model is best to be used at the system level because it can not only process the increasing complexity of system information, but is also a more general methodology that can adapt to changes.

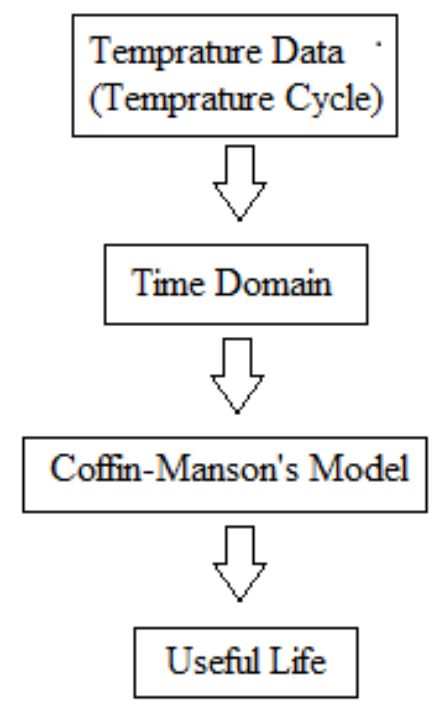

Fig 7 useful life calculations for temperature cycling data
The life cycle-based model is best used at the component level because it uses the material properties and the structure geometries of products and the environmental loads.

Fig 7 shows the one the example useful life calculation, Coffin- Manson's Model is used for the temperature cycle loading where we can apply the variable temperature ranges as per the environmental conditions and then find out the useful life of product.

Similarly there are no of Load models which we can use for the Reliability prediction.

\section{CONCLUSION}

Reliability prediction of electronic device or system is nothing but finding out product in terms of reliability safety, failure rate or the useful life. Reliability prediction includes the identification of failure modes, mechanism and causes. So it is apparent that reliability of any component, device or any system has two components i.e. probabilistic and Deterministic. In probabilistic, probability of failure and uncertainty in component are estimatedand in deterministic, the various models and causes of failures are revealed. These two components make the reliability prediction process more accurate and simple.

Reliability prediction process consist following steps

1) Identification of the life cycle load Electronic system, Device or component.

2) Identification of the failure mode, mechanism and causes and then identification of the models for respective failure mechanism i.e. FMMEA. FMMEA uses the loading life cycle of device, operating conditions and duration of application with the considerations of active stresses and failure mechanism

3) Testing the electronic system and monitoring the environmental usage data and finding the reliability of system in terms of failure or useful life.i.e. Accelerated Testing

IEEE 1413 Standards provide reliability prediction guide for accelerated testing. In accelerated testing we can use the different stress models for different loading conditions. Stress model gives us the approximate testing hours for our useful life prediction.

The data-driven model is best to be used at the system level and the life cycle-based model is best used at the component level

As per IEEE 1413 standard following are the methods which we can use for the reliability prediction of electronic system, devices or component 1) Predictions based on field data 2) Predictions based on test data 3)Prediction based on stress and damage models 4)Prediction based on handbooks. As per the application we can use the required reliability prediction method. 


\section{ACKNOWLEDGMENT}

I am thankful to my guide Dr Govind R. Kunkolienkar for his valuable suggestions and also I am thankful to Mr. Jerald Leo for his valuable input for my work.

\section{REFERENCES}

[1] "RELIABILITY" Guidelines to Understanding Reliability Prediction Revision Date: 24 June 2005, EUROPEAN POWER SUPPLY MANUFACTURERS ASSOCIATION

[2] "Reliability and MTBF Overview" Prepared by Scott Speaks Vicor Reliability Engineering

[3] "Physics Of Failure Based Approach for Predicting Life and reliability of Electronics Component" P.V.Varde, Research Reactor Service Division, issue no 313, MAR-APR 2010.

[4] "IDENTIFICATION OF FAILURE MECHANISMS TO ENHANCE PROGNOSTIC OUTCOMES" Sony Mathew, Mohammed Alam, and Michael PechtCenter for Advanced Life Cycle Engineering (CALCE), University of Maryland

[5] "Prognostics and Health Management of Electronics "Michael Pecht, Center for Advanced Life Cycle Engineering (CALCE), University of Maryland, College Park, MD, USA

[6] Accelerated Testing of Systems and Assemblies, System Reliability Center, Copyright 2004 Alion Science and Technology. All rights reserved.

[7] "Guidelines to Understanding Reliability Prediction" Revision Date: 24 June 2005, EUROPEAN POWER SUPPLY MANUFACTURERS ASSOCIATION (Visit the EPSMA website at www.epsma.org).

[8] "A Hybrid Prognostics Methodology for Electronics Products" Sachin kumar, Myra Torres, Y.C. Chan, and Michael Pecht.

[9] "Prognostics Implementation Methods for Electronics" JieGu, University of Maryland (1) Nikhil Vichare, PhD. University of Maryland(2), Terry Tracy, Raytheon Company (3), Michael Pecht, $\mathrm{PhD}$, University Of Maryland.

[10] "IEEE Guide for Selecting and Using Reliability Predictions Based

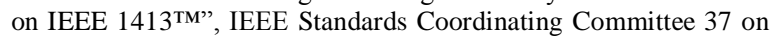
Reliability Prediction IEEE Std 1413.1 ${ }^{\mathrm{TM}}-2002$.

[11] "PROGNOSTICS AND HEALTH MANAGEMENT OF ELECTRONICS BY UTILIZING ENVIRONMENTAL AND USAGE LOADS" Nikhil M. Vichare, Doctor of Philosophy (Ph.D.), 2006

[12] "Fusion Prognostics" Rubyca Jaai ${ }^{1}$ and Michael Pecht ${ }^{2},{ }^{1}$ Prognostics and Health Management Center City University of Hong Kong, ${ }^{2}$ Center for Advanced Life Cycle Engineering (CALCE) University of Maryland

[13] "Accelerated Testing of Systems and Assemblies", System Reliability Centre 201 Mill Street Rome, NY 13440-6916.

[14] "Power Semiconductor Reliability Handbook", Alpha and Omega Semiconductor 475 Oakmead Pkwy Sunnyvale, CA 94085 U.S.A.

\section{BIOGRAPHY}

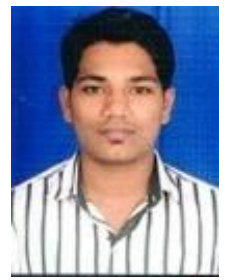

Ramesh E. Patil received the Bachelor of Engineering degree in Electrical Engg from University of Mumbai. Diploma in Electrical Engg from Government Polytechnic Kolhapur (An Autonomous Institute). Currently pursuing M.E. in Power and Energy from Goa University, Goa Employment experience include worked as lecturer in Electrical Engg, also worked as testing engineer in industry. Won a medal from University of Mumbai for graduating as a top student ( $2^{\text {nd }}$ Rank). Interest in Reliability and Electrical Engineering area. 